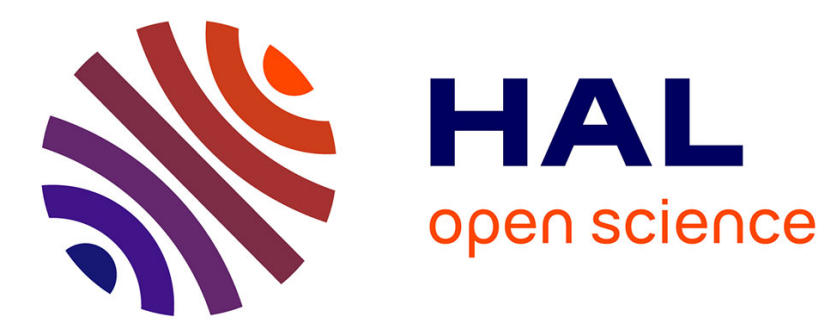

\title{
Experimental Investigation of a Platform Damper with Curved Contact Areas
}

\author{
Martin H. Jareland
}

\section{To cite this version:}

Martin H. Jareland. Experimental Investigation of a Platform Damper with Curved Contact Areas. ASME 2001 International Design Engineering Technical Conferences and Computers and Information in Engineering Conference, Sep 2001, Pittsburgh, United States. hal-02810846

\section{HAL Id: hal-02810846 https://hal.science/hal-02810846}

Submitted on 6 Jun 2020

HAL is a multi-disciplinary open access archive for the deposit and dissemination of scientific research documents, whether they are published or not. The documents may come from teaching and research institutions in France or abroad, or from public or private research centers.
L'archive ouverte pluridisciplinaire HAL, est destinée au dépôt et à la diffusion de documents scientifiques de niveau recherche, publiés ou non, émanant des établissements d'enseignement et de recherche français ou étrangers, des laboratoires publics ou privés. 


\title{
EXPERIMENTAL INVESTIGATION OF A PLATFORM DAMPER WITH CURVED CONTACT AREAS
}

\author{
Martin H. Jareland \\ Linköping University \\ Dept. of Mechanical Engineering \\ SE-581 83 Linköping, Sweden \\ E-mail:marja@ikp.liu.se
}

\section{ABSTRACT}

This paper presents a set of experiments which have been performed with a new friction damper for a high pressure turbine. The main objective of these experiments was to tune a simulation model for the current damper. The simulation model used is valid for both microslip and macroslip. A number of other topics were also investigated, such as influence of glued platforms, repeatability of an experiment, comparison of new and used dampers, and the change in surface structure of the contact areas.

A similar set of experiments has been performed earlier with the current damper. On that occasion, it was found that the experiments and simulations did not agree as desired and therefore a new set of experiments was suggested. This paper presents the new experiments and the new simulations with a more precisely tuned model. The simulation model is tuned by selecting a suitable coefficient of friction and tangential stiffness for the contact interface model. It is found that the simulations agree well with the experimental results when the normal force is held constant and the excitation force is varied. The properties of the contact, contact area and pressure, are unchanged when the normal force is constant.

If a new damper is compared with a damper that has been used in a series of experiments, it is found that the resonance shifts to a lower frequency and that the amplitude increases. This is probably caused by a decrease in coefficient of friction due to wear of the contact surfaces.

The repeatability of an experiment has been investigated by running the same experiment five times in succession. It was found that the repeatability was very good if the position of the damper was not changed. The differences that were found were mainly due to wear on the contact surfaces. A comparison of sweeping forward or backward in frequency was also performed. It showed that the difference was small both for experiments with small motions in the contacts and for experiments with a high amount of macroslip.

\section{INTRODUCTION}

One of the main problems with jet engines in service is high-cycle fatigue of turbine blades due to resonance vibrations within the operating range of the engine. A number of actions can be taken to increase the reliability of the turbine: improve the material properties of the blades, design the blades to avoid resonance vibrations, modify the flow through the turbine and finally, increase the amount of damping in the system. This paper focuses on the use of friction damping to improve the life of turbine blades. Other types of damping that exist in a turbine stage are material and aeroelastic damping. The proportion of each type of damping in the relation to the total amount of damping may vary greatly between different turbines and different running conditions.

A number of methods can be used to increase the amount of friction damping in a bladed disk, see the review of friction damping in bladed disks by Griffin [1]. In a turbine stage, the most common method is to use a specific damping device, in the form of a piece of metal arranged in a cavity underneath the platform of the blades. The friction damper is pressed against two adjacent platforms by centrifugal force when the turbine is running. Friction damping arises when a relative motion occurs between the blades. This type of damper is also often called a platform damper due to its position underneath the platforms.

The damper studied in the current paper is a so-called curved wedge damper. The configuration of the platforms and the current blade-toblade damper is shown in Fig. 1. The characteristics of this configuration are that the platforms have an inclined contact area and the contact surfaces on the damper are curved. The inclination of the platforms makes the damper self-centering when centrifugal force is acting on it.

Turbine stages with platform dampers have been studied by a number of researchers, both theoretically and experimentally. The most commonly used simulation model for friction contacts is the macroslip model, which implies that the contact is either stuck or fully slipping. This model has been used by Muszynska and Jones [2], Griffin [3] and Yang and Menq [4,5]. For a platform damper, the displacements are small and the normal force high. It is therefore most likely that partial 


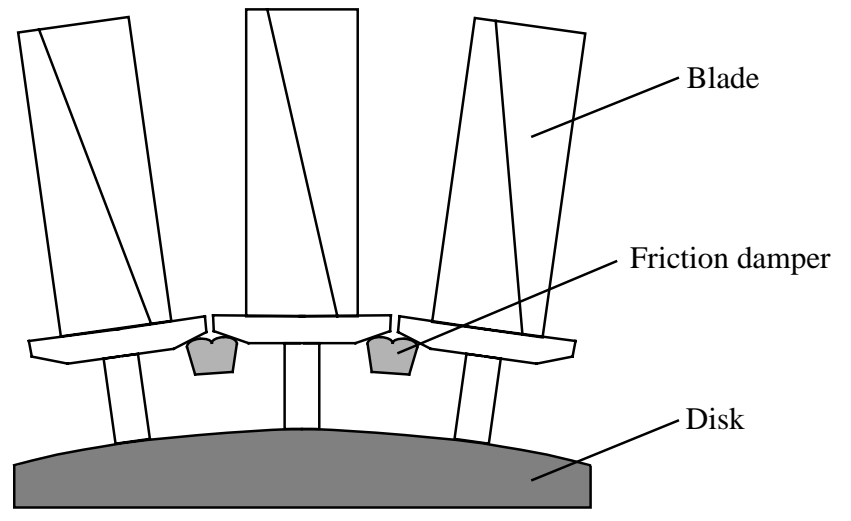

Figure 1 A schematic view of a bladed disk with curved wedge dampers.

slip will occur in the contact, which is denoted microslip. This phenomenon has been included in dynamic analysis of turbine stages by researchers such as Csaba [6], Menq et al. [7] and Sanliturk et al. [8]. Platform dampers have also been modelled with discrete friction interface models based on the Hertzian solution, see Csaba [9], Sextro et al. [10] and Panning et al. [11].

\section{BACKGROUND}

A new damper has been designed at Volvo Aero Corporation for the RM8B HP-turbine. This damper has been tested in spin-pit tests and in engine tests by Volvo Aero Corporation. Csaba and Andersson [12] studied the current damper both theoretically and in spin-pit tests to find the optimal damper mass. They modelled the friction interfaces with the Bar model developed by Csaba [13], which is valid for both microslip and macroslip. The same friction interface model has been used by Jareland and Csaba [14] to study mistuning of a bladed disk due to variations in the properties of the dampers.

A new friction interface model for curved friction contacts has been developed in a research project at Linköping University, Sweden, by Csaba [9]. This is a discrete friction interface model and is denoted the Brush model. The properties of the discrete contact points are based on the Hertzian solution for the contact. This model is valid for both microslip and macroslip, which is important in modelling platform dampers. A disadvantage of the Bar model is that it can only be used for cases with motion in a single dimension. The Brush model is suitable when a more general motion is present in the contact.

In order to verify the Brush model, experiments were carried out at Imperial College, London, see Csaba [9]. These experiments were performed as part of the research program Mechanical Friction Damping, which was financially supported by the Rolls-Royce Aerospace Group and Volvo Aero Corporation. The research was carried out at the Imperial College of Science, Technology and Medicine, Centre of Vibration Engineering and Linköping University, Mechanical Engineering Department, Division of Machine Design.

During the evaluation of the experimental results, it was found that the simulations and experiments did not agree as desired. Differences in both resonance frequency and amplitude were found. Some modifications of the test procedure were recommended in the evaluation and a new series of experiments was suggested. The two main questions that arose in the evaluation of the experiments were:

- Does the glue, which was used to mount the platforms on the beams, provide damping to the system? To investigate this, a new set of beams with soldered platforms was manufactured. Due to the fact that solder provides a lower amount of material damping than polymers in general.

- The properties of the contacts are changed when the normal force is changed. How will this influence the result? It is therefore suggested that instead the normal force be kept constant and the excitation force varied.

The main objective of this new series of experiments is to investigate these topics. A number of other topics are also investigated, such as repeatability of an experiment, comparison of new and used dampers, and changes in the surface structure of the contact areas.

\section{EXPERIMENT SET-UP}

A schematic view of the test rig is shown in Fig. 2 and a photo in Fig. 3. A more detailed description of the test rig can be found in Csaba [9] and therefore only a brief presentation is given here. The test rig consists of two beams clamped to an inertia block, which is located on a frame foundation with rubber in between. The damper is located between the blades and loaded with a weight against the platforms. The platforms are made of the same material as the real blade platforms. Two sets of beams have been used: one set with the platforms glued on and one set with the platforms soldered on.

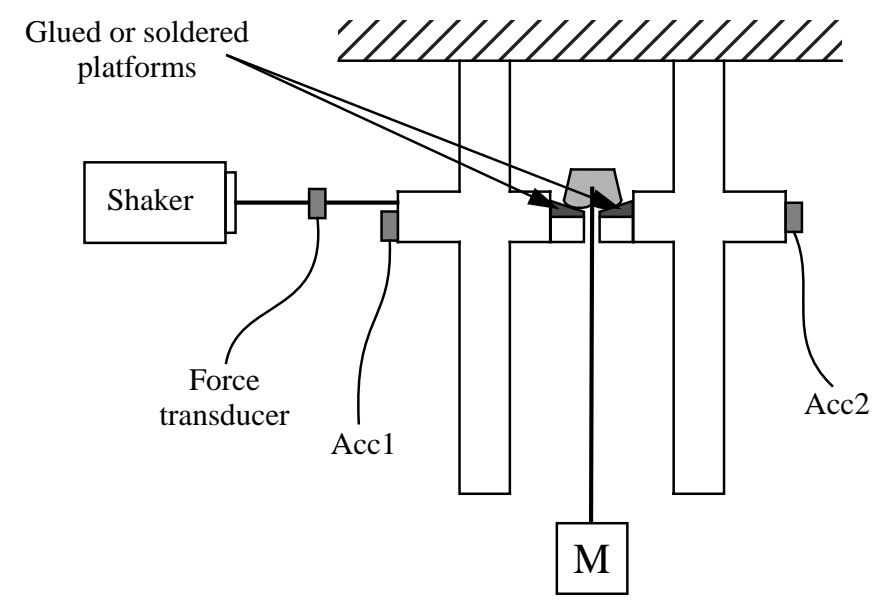

Figure 2 Beam-Damper-Beam test rig.

To check how well these two sets of beams are tuned, a modal analysis of the system, without the damper, was performed. It was found that the out-of-phase natural frequency is located at $530.2 \mathrm{~Hz}$ and the inphase mode at $544.4 \mathrm{~Hz}$ for the beams with glued platforms. For the beams with soldered platforms the out-of-phase mode is at $509.5 \mathrm{~Hz}$ and the in-phase mode at $522.6 \mathrm{~Hz}$. It is also found that the damping in the system, without the damper, for the out-of-phase mode is approximately $0.015 \%$ and $0.07 \%$ for the glued and soldered platforms, respectively. 


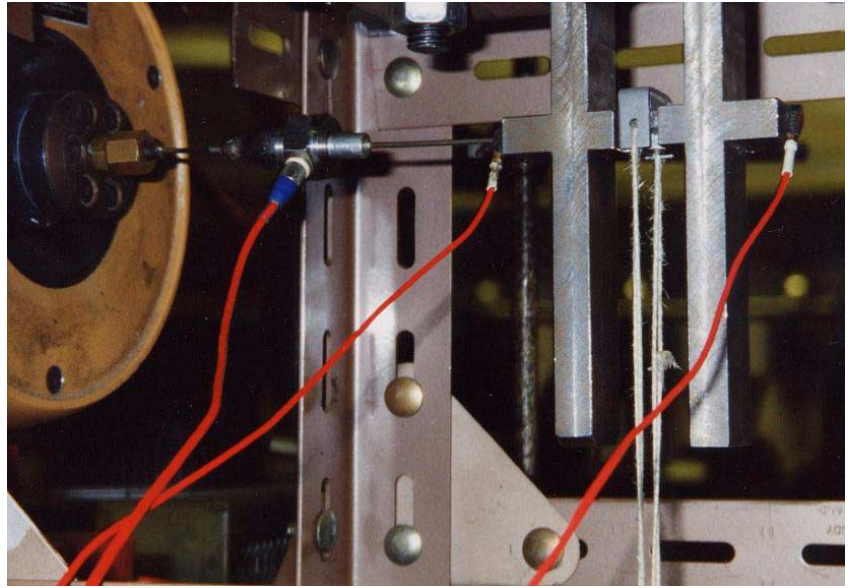

Figure 3 Test rig at Imperial College.

The excitation force is generated by a shaker and applied through a push rod on one of the beams. The applied excitation force is measured with a force transducer on the push rod and the responses are measured with two accelerometers, one mounted on each platform. A PC with the MODACQ software is used to control the experiment. The MODACQ software is part of the ICATS software package for modal analysis, developed at Imperial College, London. The system performs a sine sweep over the current frequency range with a fixed frequency step to generate the forced response function. This can be performed either forward or backward in frequency. In all the experiments, a broad sweep is first performed forward and a fine sweep is then performed backward in frequency, except for the comparison of forward and backward sweeping. The software controls the excitation force at the desired level during the experiment. The response is measured at each frequency and averaged over 100 cycles with a delay of $0.1 \mathrm{sec}$.

\section{TEST PROGRAM}

The test program covered normal loads $N=20,36,50,100,150 \mathrm{~N}$ and experiments without the damper attached. The excitation forces used are $F=1,2,5,10,15,20 \mathrm{~N}$. The frequency range was set to cover the out-of-phase mode and go close to the in-phase resonance frequency. The frequency ranges used are $550-850 \mathrm{~Hz}$ and $529-850 \mathrm{~Hz}$ for the beams with glued and soldered platforms, respectively. A fixed frequency step of $3 \mathrm{~Hz}$ was used, except for a few cases with a high excitation force, where a frequency step of $6 \mathrm{~Hz}$ was used. In some experiments, the in-phase resonance frequency was included, but it was difficult for the system to control due to the low amount of damping that was provided in these cases.

The equipment used for the test consisted of two sets of beams and two new dampers. The first set of experiments was performed with the beams with glued platforms in order to make a comparison against previous results. For this case, the excitation force $1 \mathrm{~N}$ and the normal forces $20 \mathrm{~N}, 50 \mathrm{~N}$ and $100 \mathrm{~N}$ were used.

A uniform load intensity along the contact is desirable and it is therefore important for the set-up to be exactly level. It was also assumed that when the damper is new it will start to wear and debris will be found in the contact interfaces. This will affect the properties of the contact, i.e. the coefficient of friction. The contact surfaces on the damper and the blades were therefore cleaned with alcohol before each experiment. This enabled more reliable results to be obtained from the experiments.

Initially, the beams with glued platforms were tested with a new damper, after which the beams were replaced by the set with soldered platforms. A similar set of loads was used to investigate whether the glue provided damping to the system. Several sets were then performed with a new damper in order to generate forced response functions that could be used to verify the simulation model and to check the difference between a new and a used damper.

The beams were then replaced again by the set with glued platforms. Initially, a set of tests with the excitation force fixed at $2 \mathrm{~N}$ and different normal loads was performed. This was found to be difficult to carry out, since the position of the damper was changed when it was cleaned. Therefore, the normal load was fixed and the experiment was first performed with the lowest excitation force, which was increased until the highest requested excitation force was reached. It was assumed that it would be preferable only to clean the damper before the first experiment and to keep the same position of the damper for all excitation forces. This was found to work well because there are small movements in the contact interfaces for low excitation forces and therefore a lower influence from wear.

Finally, a number of experiments were performed to check the repeatability of a particular experiment. This was done for the normal force $100 \mathrm{~N}$ and the excitation forces $5 \mathrm{~N}$ and $1 \mathrm{~N}$. The same set-up was tested five times. A final experiment was made in order to check the difference between sweeping forward and sweeping backward in frequency.

\section{RESULTS}

The results and evaluation of the experiments are presented in this section. The main objective of this study is to tune the simulation model for the current damper. Therefore, the experimental results are compared here with simulations using the damper model developed by Csaba [9]. A number of other topics are also studied, e.g. influence of glued platforms, comparison of new and used damper, and repeatability of an experiment.

\section{Influence of glued platforms}

It was found in the experiment that the glue did not influence the result in any notable way. In Fig. 4, the forced response function is shown for both the set-ups, with glued and soldered platforms, respectively. The result is shown for the normal force $100 \mathrm{~N}$ and different excitation forces. It can be seen that there is a shift in the frequency, which is due to the difference in natural frequencies of the two sets of beams.

The differences in the results between glued and soldered platforms are small for all excitation forces, except the highest. In fact, the set with glued platforms shows a slightly higher resonance amplitude for the excitation forces 2,5 and $10 \mathrm{~N}$. This is probably caused by the lower amount of damping that was found in the modal analysis of the beams with glued platforms, without damper. It can also be seen that it was difficult for the system to control the excitation force for high levels, i.e. 10 and $20 \mathrm{~N}$. 


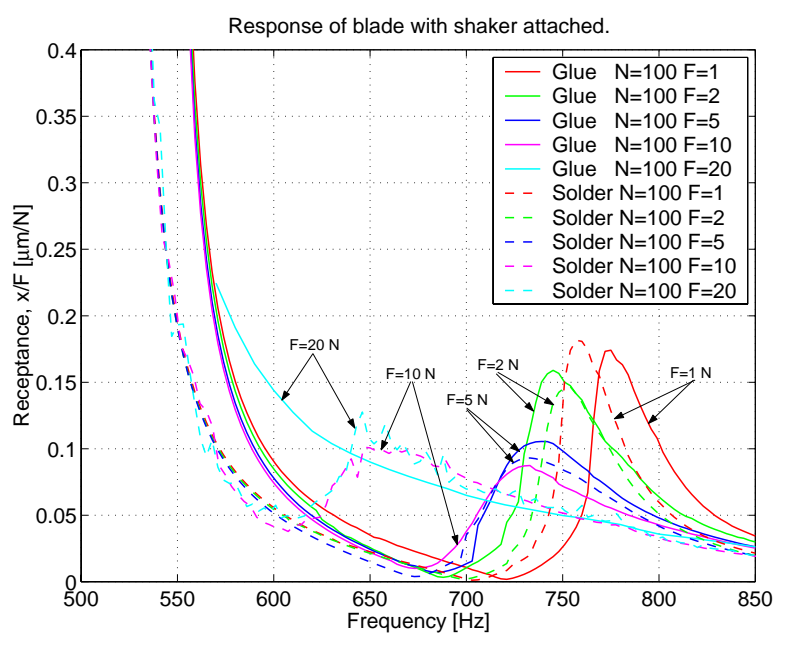

Figure 4 Comparison of glued and soldered platforms.

The conclusion is that the influence of glued or soldered platforms is very small and that there are other parameters that have a much greater effect on the response of the system.

\section{Comparison of new and used damper}

Figure 5 shows the response for a new damper and for a damper that has been used in a number of experiments. The normal force $100 \mathrm{~N}$ is used and the excitation force is varied from $1 \mathrm{~N}$ to $20 \mathrm{~N}$. It can be seen that the resonance peaks are shifted to lower frequencies and that the resonance amplitudes are increased, for the damper that has been used in a number of experiments.

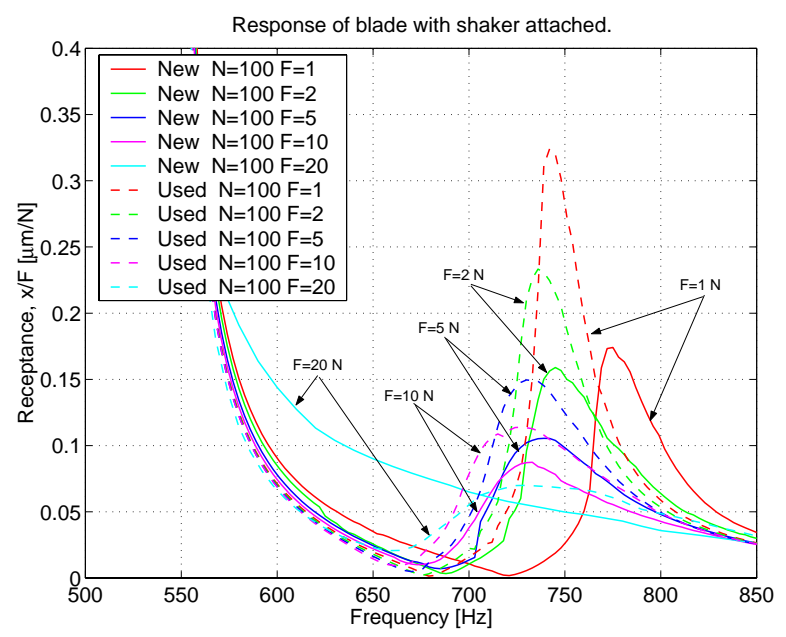

Figure 5 Comparison of new and used damper.

The explanation is that when the damper has been used for a time it becomes worn and the properties of the contact surfaces change. The contact area on the damper is increased and smoothed. The decrease in the surface roughness of the contact surfaces will probably lead to a decrease in the coefficient of friction. This affects the response of the system in the same way as a decrease in the normal load. The resonance peaks are therefore shifted to lower frequencies and the amplitudes are found to increase, which is the case when macroslip is dominating.

\section{Comparison of simulation and experiment}

The experimental and the simulation results did not agree as desired for the previously performed experiments, see Csaba [9]. The simulation model has now been tuned more precisely for the current damper and the test procedure is also better known. The simulation model is in principle the same as that used in the evaluation of the experiments performed earlier. It is presented in detail by Csaba [9] and therefore only briefly discussed in this paper.

The two beams, representing turbine blades in the experiment, are modelled with beam elements in the simulation model. The nonlinear equation of motion for the system is solved with the Harmonic Balance Method, HBM. This method is the most commonly used solution technique for simulation of bladed disks with platform dampers; see for example Sanliturk et al. [15], Csaba [16] and Panning et al. [11].

The properties of the damper are described here as a complex stiffness, which is assembled into the dynamic stiffness matrix for the beam model. The damper is modelled with two friction interfaces connected by a linear spring, $k_{x x}$, representing the elasticity of the damper body, see Fig. 6 . The friction interfaces are modelled with the so-called Brush model presented by Csaba [9]. In this model, the basic idea is to model the contact as a number of discrete contact points, bristles, each with a stiffness in the normal and the tangential direction. This is shown on the left in Fig. 6, where each discrete contact is represented by a spring.
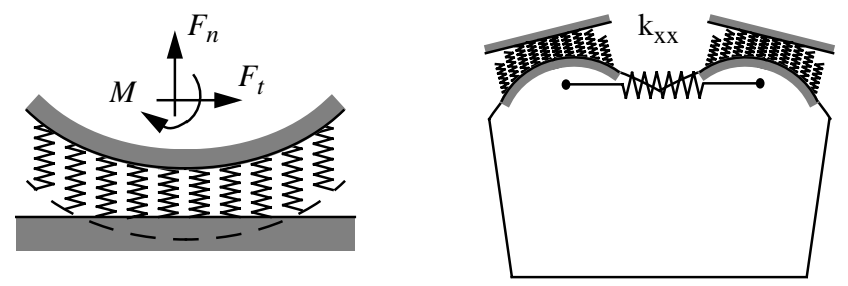

Figure 6 Friction interface model in two dimensions (left) and damper model (right).

The stiffnesses in the normal and the tangential directions are given by the following expressions

$$
\begin{aligned}
k_{n} & =\gamma_{n} E^{*} A / b \\
k_{t} & =\gamma_{t} E^{*} A / b
\end{aligned}
$$

where $E^{*}, A$ and $b$ are the combined modulus, bristle contact area and the shorter semi-axis for the Hertzian solution without friction. The quantities $\gamma_{n}$ and $\gamma_{t}$ are non-dimensional stiffness coefficients. The coefficient $\gamma_{n}$ can be set so that either the maximum pressure or the contact area corresponds to the Hertzian solution for the contact, see Csaba [9]. The criterion of the same contact area as the Hertzian solution is used in these simulations, which implies $\gamma_{n}=1.18$. The coefficient $\gamma_{t}$ is more uncertain and is therefore one of the parameters used to tune the simulation model. 
The force in the tangential direction over bristle $k$ is found as

$$
f_{t}(k)=\left\{\begin{array}{llc}
k_{t}(w(k, 1)-v(k, 1)) & \text { if } \quad k_{t}(w(k, 1)-v(k, 1))<\mu f_{n}(k) \\
\mu F_{n}(k) & \text { if } \quad k_{t}(w(k, 1)-v(k, 1)) \geq \mu f_{n}(k)
\end{array}\right.
$$

where $w$ and $v$ are the coordinates for the contact point and the bristle attachment point, respectively.

The coefficient of friction and the tangential stiffness are two uncertain parameters. These parameters are therefore selected for tuning of the simulation model. The coefficient of friction 0.35 and tangential stiffness coefficient $\gamma_{t}=0.03^{*} \gamma_{n}$ were found to give the best agreement between experiment and simulation. It was also assumed that the radius of the contact surface on the damper increases due to wear. Therefore the radius $26 \mathrm{~mm}$ is used in the simulations instead of $2.6 \mathrm{~mm}$, which is the original radius. This modification had a minor influence on the simulation results. The comparison of experiment and simulation for the normal forces $36 \mathrm{~N}, 50 \mathrm{~N}$ and $100 \mathrm{~N}$ is shown in Fig. 7, Fig. 8 and Fig. 9 , respectively. The experimental results are marked $\mathrm{X}$ and the simulation results are marked $\mathrm{A}$.

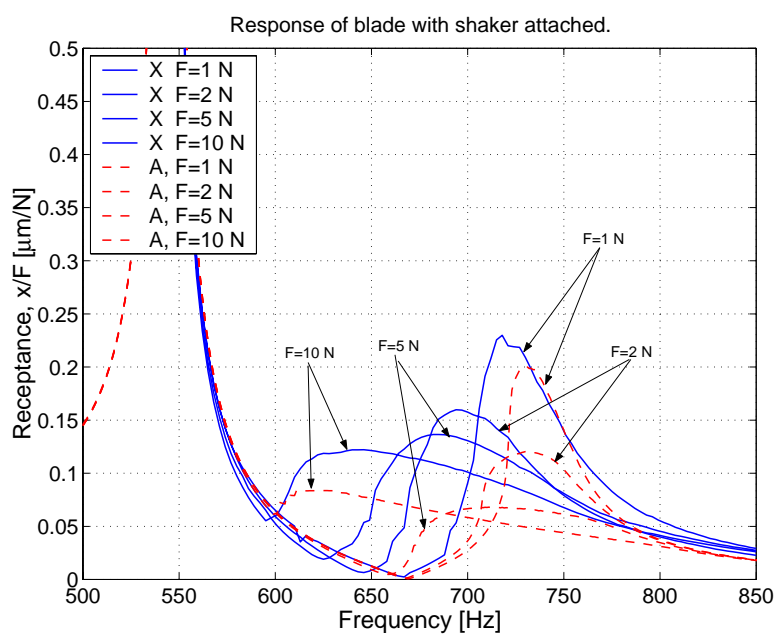

Figure 7 Comparison of experiment and simulation for the normal load $36 \mathrm{~N}$.

It can be seen that the correspondence between experiment and simulation is relatively good. The simulation model was tuned for the normal load $100 \mathrm{~N}$ and the excitation force amplitude $2 \mathrm{~N}$. The correspondence is found to be a slightly poorer for the normal forces 36 $\mathrm{N}$ and $50 \mathrm{~N}$, which are very low normal forces.

The experimental and simulation results now correspond better than after the previous experiments and simulations, both in frequency and amplitude. This is mostly due to the more precise tuning of the simulation model. However, it is difficult to judge whether the tuned simulation model is valid for simulation of the damper performance under the actual conditions existing in the jet engine. It is most likely that another tuning of the simulation model is needed for the real case, in which the normal load is about ten times larger, the temperature is higher and the damper is more or less worn.

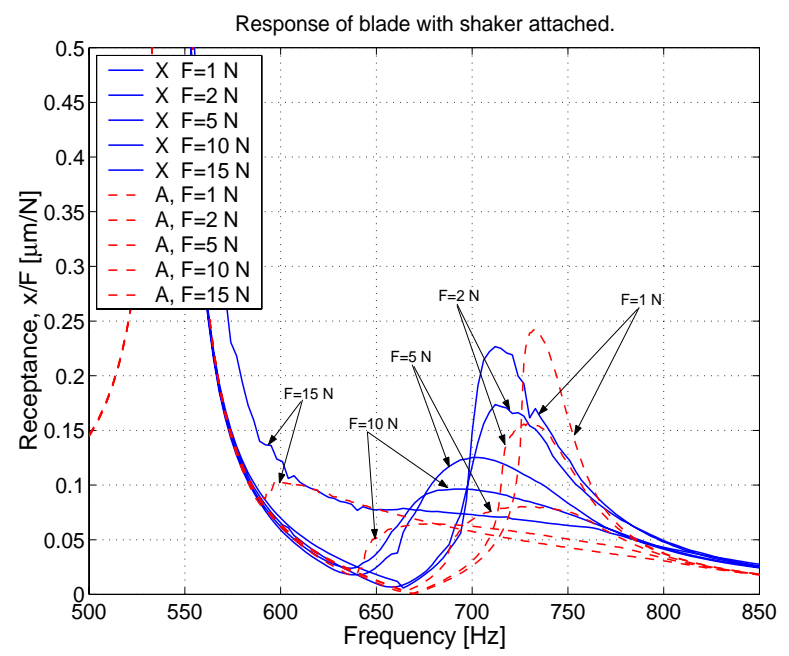

Figure 8 Comparison of experiment and simulation for the normal load $50 \mathrm{~N}$.

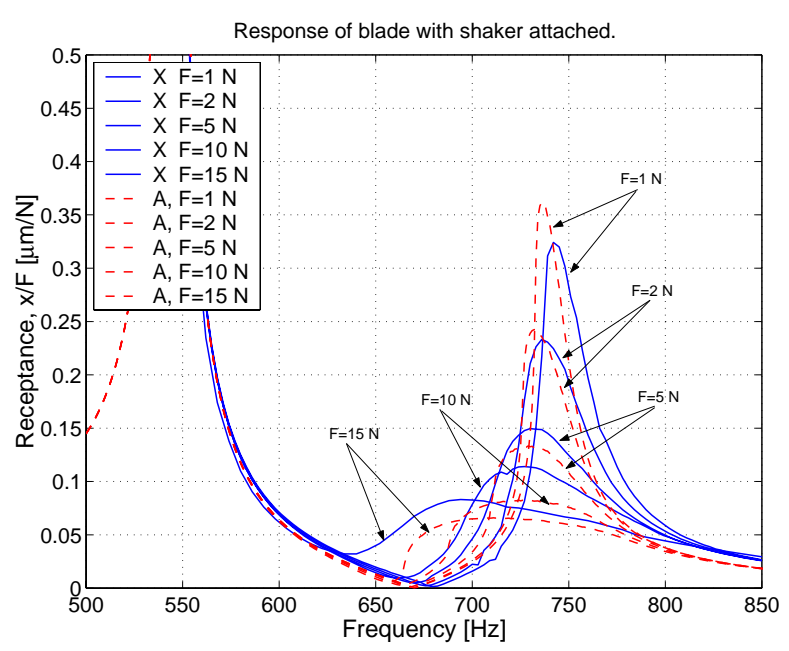

Figure 9 Comparison of experiment and simulation for the normal load $100 \mathrm{~N}$.

\section{Repeatability}

A repeatability test was performed to check how well the results correspond if the same experiment is repeated a number of times. The same experiment was therefore performed five times, without changing the position of the damper. This was done for two different load sets, both with the normal load $100 \mathrm{~N}$. The first used the excitation force $5 \mathrm{~N}$ and the second $1 \mathrm{~N}$. The response for the first case is shown in Fig. 10 and for the second case in Fig. 11.

It can be seen in the first case, $5 \mathrm{~N}$, that the resonance frequency shifts slightly to a lower frequency. A small increase in amplitude was also observed when the experiment was repeated. This could be due to debris in the contacts as a result of wear, smoothing of the contact surfaces and/or increased contact area. If the changes are caused by smoothing of the contact surfaces, which is most likely, it can be expected that the amount of gradual change will decrease when the 


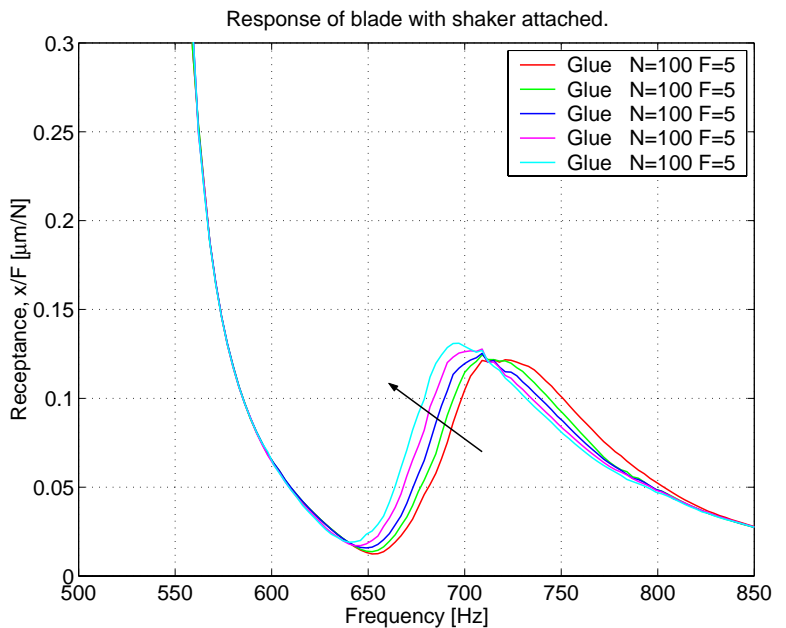

Figure 10 Five repeated experiments with $N=100 N$ and $F=5 N$.

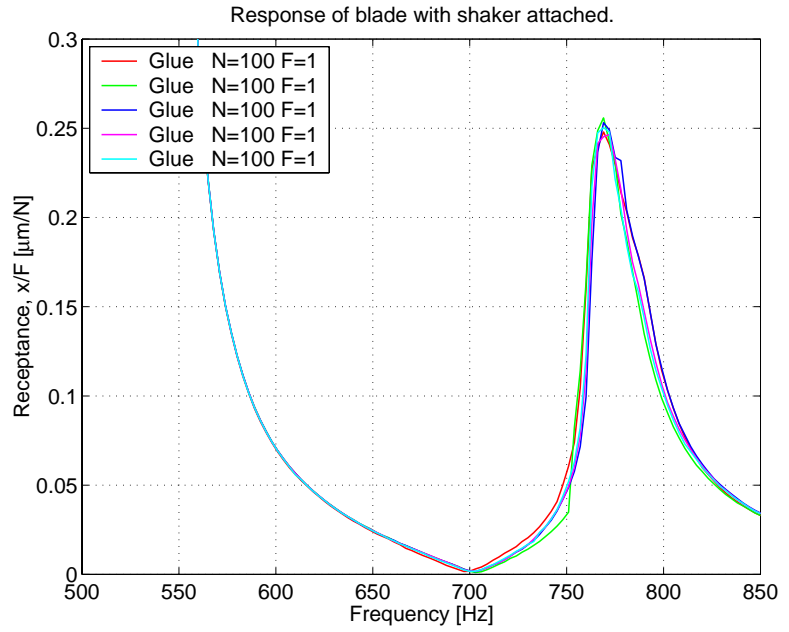

Figure 11 Five repeated experiments with $N=100 \mathrm{~N}$ and $\mathrm{F}=1 \mathrm{~N}$.

surface roughness is decreased. This process will proceed more rapidly under the conditions in the engine and an equilibrium state will probably occur. In this experiment, the contact surfaces were not cleaned before each experiment. The reason for this was that the same position of the damper was desired for all experiments. The same set of experiments was performed with the contact surfaces cleaned before each run. These experiments did not show satisfactory repeatability, due to a new position of the damper for each run.

For the case with the lower excitation force, $1 \mathrm{~N}$, it can be seen that the result does not change very greatly between the experiments. This is due to the fact that there are very small motions in the contact and therefore very little influence from wear during the experiment. The conclusion is that the position of the damper influences the experimental result more than wear on the contact surfaces.

\section{Sweeping forward and backward in frequency}

Due to the time history dependency for a friction contact, it is of interest to investigate the difference between sweeping forward and backward in frequency. This was studied for the same load cases as the repeatability tests. Figure 12 shows the result of the case with normal force $100 \mathrm{~N}$ and excitation force $5 \mathrm{~N}$. The contact surfaces were not cleaned between the experiments.

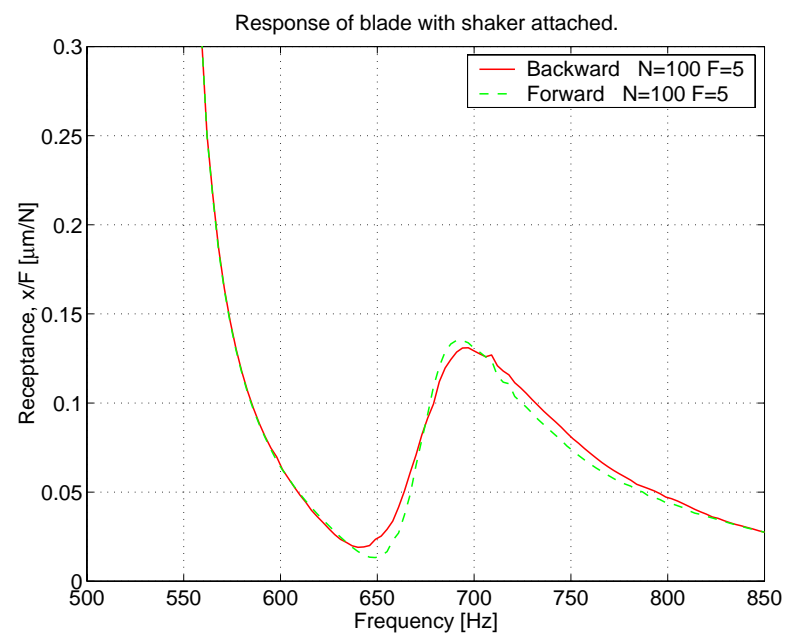

Figure 12 Sweeping forward or backward in frequency.

It can be seen that sweeping forward or backward in frequency has only a limited influence on the result. For the case with the excitation force $1 \mathrm{~N}$, the influence of sweeping forward or backward in frequency is not notable, owing to the small amount of slip in the contacts.

\section{SURFACE STRUCTURE}

The used dampers and platforms were studied in a Scanning Electron Microscope, SEM. A number of pictures were taken of the contact surfaces. Figure 13 shows the contact surface on one of the dampers and Fig. 15 the contact surface on one of the platforms. The sliding direction is marked with a white arrow in both figures.

Figure 13 shows that the contact surface on the damper is smoothed compared to the original surface structure. This is due to wear of the contact surface, which reduces the surface roughness. An example of the surface profile of one contact region of the damper is shown in Fig. 14. It can clearly be seen where the contact has occurred and that the surface is smoothed. The inclination of the contact region is about $14^{\circ}$ and the length of the contact zone is about $0.25 \mathrm{~mm}$.

The smoothing of the contact surface will most probably reduce the coefficient of friction and thereby influence the dynamic behaviour of the system when the damper is in use. A decrease in coefficient of friction influences the system in the same way as a decrease in normal load, under the assumption that the Coulomb friction law is valid. Hence, the resonance frequency is shifted to a lower frequency and the resonance amplitude increases when the damper is worn. This is the case when macroslip is dominant. For the current damper, this phenomenon is found when a new and a used damper are compared, see Fig. 5. The conclusion is that this behaviour is caused by a decrease in coefficient of friction due to smoothing of the contact surfaces. 


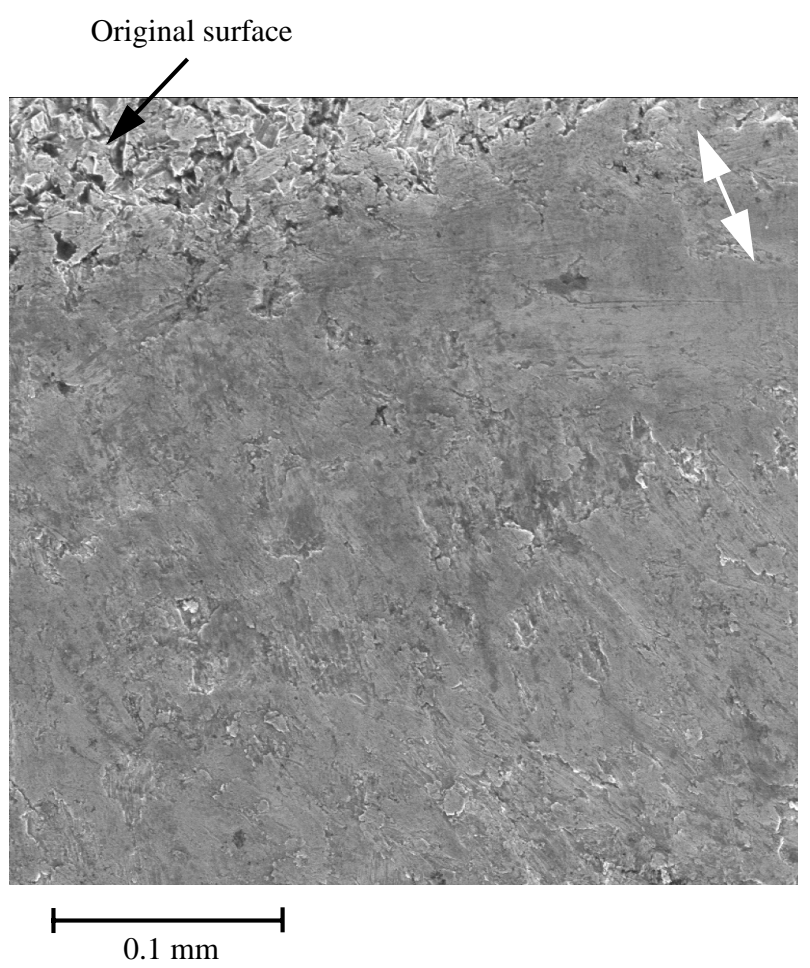

Figure 13 Part of the contact surface on the damper.

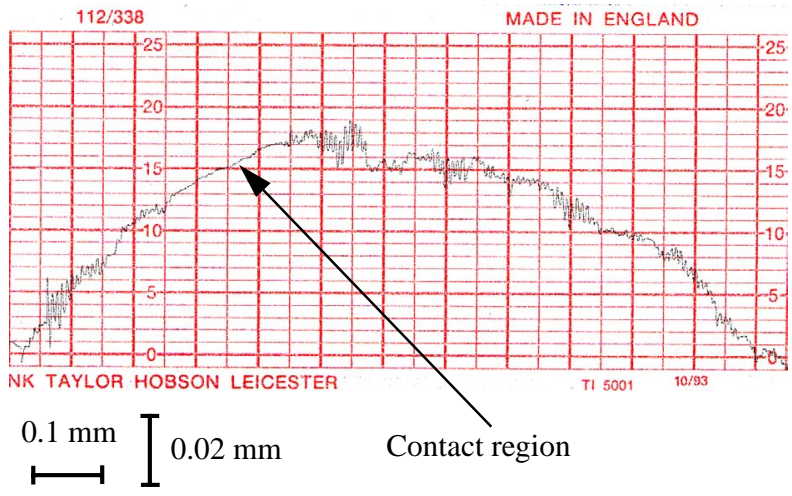

Figure 14 Surface profile of contact region on damper.

For the real load case, the wear process is expected to be different to that found in the experiment. The normal load on the damper in the jet engine is approximately ten times higher than that used in these experiments. In that case, the initial wear process will proceed more rapidly and the influence of the surface roughness is therefore expected to be smaller. The coefficient of friction will probably decrease initially and then approach a constant value fairly quickly. On the other hand, surface oxidation, temperature level and/or variation of normal pressure will influence the coefficient of friction and the wear process for the damper under actual conditions.

Figure 15 shows part of the contact surface on one of the platforms. The cutting marks from machining of the part can clearly be seen. It can also be seen that the contact has only occurred on the highest regions of the contact surface. As expected, the actual contact area is therefore concluded to be much smaller than the nominal contact area. Marks in the sliding direction can also be seen, which is caused by hard debris in the contact. Smearing of damper material on the platform is indicated. It is concluded that the wear process is a combination of adhesive and abrasive wear.

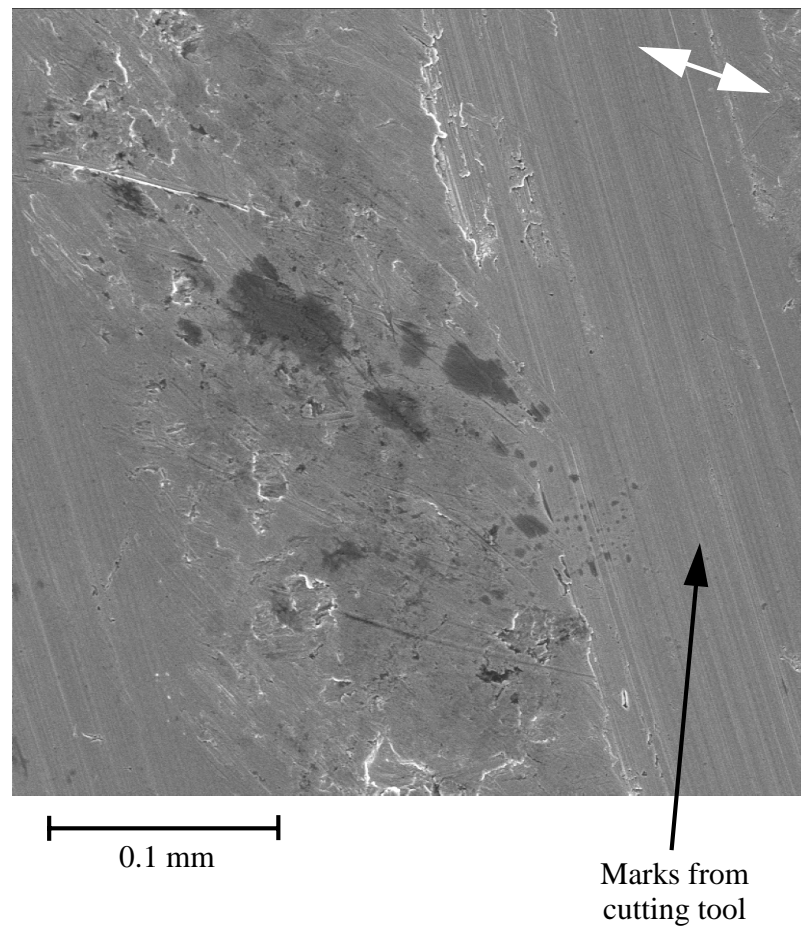

Figure 15 Part of the contact surface on the platform.

The conclusion is that the properties of the contact surfaces change during the experiments. This is a complicated process comprising a large number of phenomena, which influence the coefficient of friction and the wear process.

\section{DISCUSSION AND CONCLUSIONS}

A number of topics concerning the new platform damper for the HP-turbine in the RM8B engine have been investigated in the current work, both experimentally and theoretically. The same damper has been studied earlier in a similar set of experiments by Csaba [9].

In the previous experiments, beams with platforms glued to them were used. One question that arose after these experiments was whether the glue provided damping to the system and thereby influenced the correspondence between experiment and simulation. A new set of beams with soldered platforms was therefore manufactured and used in the new set of experiments. It was found that the glue did not influence the result in any notable way. Alignment of the damper, properties of the contact surfaces and other types of damping than friction damping in the system had a greater influence on the result than the glue. The conclusion is that beams with glued platforms can be used if the experiments are to be repeated. 
A comparison between a new and a used damper was also performed. It was found that the resonance peak shifts to a lower frequency and to a higher amplitude when the damper is worn. This is caused by a decrease in coefficient of friction, due to wear on the contact surfaces.

The correspondence between the results achieved with the tuned simulation model and the experiments is relatively good and certainly better than after the previous experiments and simulations. The simulation model was tuned by selecting a proper coefficient of friction and tangential stiffness for the bristles. Unfortunately, is it uncertain whether the same values can be used in simulation of damper performance under the actual conditions in the jet engine, in which case the normal load is about ten times greater.

A number of experiments were also performed to investigate the repeatability of the experiments and the difference between sweeping forward or backward in frequency. It was found that the repeatability of an experiment was very good if the position of the damper was not changed between the experiments. The difference that occurred was caused by wear of the contact surfaces. The difference between sweeping forward and backward in frequency was found to be small.

If a new set of experiments is planned for the current or a similar damper the following recommendations are made:

- Perform experiments with a damper that has been used in the jet engine in order to compare a new damper with one that has been used under the actual conditions. The purpose of this recommendation is to determine whether the surface structure has a significant influence on performance and also to avoid initial wear on the damper.

- If possible, use the same normal pressure in the contact that is present in the engine to avoid influence of the normal pressure on the coefficient of friction. This can be done either by using the same normal load on the damper as in the engine or by decreasing the size of the nominal contact area. The first alternative corresponds best with the real case and is therefore the preferred one. For the current damper, is this not possible to perform in the present test rig and a new test rig would be needed.

\section{ACKNOWLEDGMENTS}

The author of this paper wishes to thank Professor Karl-Olof Olsson, Head of the Division of Machine Design, Linköping University, for his supervision and helpful discussions. The author also wishes to thank Gabor Csaba, Volvo Aero Corporation, for his major contributions to the presented work and Anthony Stanbridge, Imperial College, London, for his support and assistance during the experimental work. This work was financially supported by the National Aeronautical Research Program under grant NFFP-348 and has been carried out at Linköping University in co-operation with Volvo Aero Corporation.

\section{REFERENCES}

[1] Griffin J. H., 1990, "A Review of Friction Damping of Turbine Blade Vibration", International Journal of Turbo and Jet Engines, Vol. 7, pp. 297-307
[2] Muszynska A., Jones D. I. G., 1983, “On Tuned Bladed Disk Dynamics: Some Aspects of Friction Related Mistuning", J. of Sound and Vibration, Vol. 86(1), pp. 107-128

[3] Griffin J. H., 1980, "Friction Damping of Resonant Stresses in Gas Turbine Engine Airfoils", J. of Vibration and Acoustics", Vol. 112(2), pp. 175-182

[4] Yang B. D., Menq C. H., 1997, "Characterization of Contact Kinematics and Application to the Wedge Dampers in Turbomachinery Blading, Part I: Stick-Slip Contact Kinematics", ASME Turbo Expo '97, Orlando, Florida, USA, June 2-5 1997, paper 97-GT-19

[5] Yang B. D., Menq C. H., 1997, "Characterization of Contact Kinematics and Application to the Wedge Dampers in Turbomachinery Blading, Part II: Prediction of Forced Response and Experimental Verification", ASME Turbo Expo '97, Orlando, Florida, USA, June 2-5 1997, paper 97-GT-20

[6] Csaba G., 1995, "Microslip Friction Damping with Special Reference to Turbine Blade Vibrations", LiU-Tek-Lic-1995:09, ISBN 91-7871-507-5, Linköping University, Sweden

[7] Menq C.-H., Bielak J., Griffin J. H., 1986, "The Influence of Microslip on Vibratory Response, Part I: A New Microslip Model", J. of Sound and Vibration, Vol. 107(2), pp. 279-293

[8] Sanliturk K. Y., Ewins D. J., Stanbridge A. B., 1999, "Underplatform Dampers for Turbine Blades: Theoretical Modelling, Analysis and Comparison with Experimental Data", ASME Turbo Expo '99, Indianapolis, Indiana, USA, June 7-10 1999, paper 99-GT-335

[9] Csaba G., 1999, "Modelling of a Microslip Friction Damper Subjected to Translation and Rotation", ASME Turbo Expo '99, Indianapolis, Indiana, USA, June 7-10 1999, paper 99-GT-149

[10] Sextro W., Popp K., Wolter I., 1997, "Improved Reliability of Bladed Disks due to Friction Dampers", ASME Turbo Expo '97, Orlando, Florida, USA, June 2-5 1997, paper 97-GT-189

[11] Panning L., Sextro W., Popp K., 2000, “Optimization of Interblade Friction Damper Design”, ASME Turbo Expo '00, Munich, Germany, May 8-11 2000, paper 2000-GT-541

[12] Csaba G., Andersson M., 1997, "Optimization of Friction Damper Weight, Simulation and Experiments", ASME Turbo Expo '97, Orlando, Florida, USA, June 2-5 1997, paper 97-GT-115

[13] Csaba G., 1995, "Friction Damping of Turbine Blade Vibrations Using a Microslip Model", J. of Machine Vibration, Vol. 4, pp 2-7

[14] Jareland M. H., Csaba G., 2000, "Friction Damper Mistuning of a Bladed Disk and Optimization with Respect to Wear", ASME Turbo Expo '00, Munich, Germany, May 8-11 2000, paper 2000-GT-363

[15] Sanliturk K. Y., Imregun M., Ewins D. J., 1997, "Harmonic Balance Vibration Analysis of Turbine Blades with Friction Dampers", Trans. ASME, J. of Vibration and Acoustics, Vol. 119, pp. 96-103

[16] Csaba G., 1998, "Forced Response Analysis in Time and Frequency Domain of a Tuned Bladed Disk with Friction Dampers", J. of Sound and Vibration, Vol. 214(3), pp. 395-412 